\title{
Association of Fibroblast Growth Factor-23 and Early Detection of Breast Arterial Calcification in Different Stages of Chronic Kidney Disease Patients
}

\author{
Basma O. Ibrahim¹, Gamal A. Tawfik¹, Housseini M. Ahmed², and \\ Hamdy H. Omar ${ }^{*}$
}

${ }^{1}$ Department of Internal Medicine and Nephrology, Faculty of Medicine, Suez Canal University, and ${ }^{2}$ Department of Diagnostic Radiology, Faculty of Medicine, Suez Canal University

\begin{abstract}
Background: Vascular calcification (VC) plays a major role in cardiovascular disease (CVD), which is one of the main causes of mortality in patients with chronic kidney disease (CKD). During the early stages of CKD, Fibroblast growth factor-23 (FGF-23) levels increase to keep serum phosphorus within the normal range. FGF23 may be associated with death and cardiovascular events in CKD patients. Aim: The study aimed at early detection of breast arterial calcification (BAC) and higher levels of FGF-23 as indicators of systemic VC in patients with different stages of CKD. Methodology: The patients were divided into 3 groups; representing stages 2, 3 \& 4 of CKD women, and the $4^{\text {th }}$ group was considered as a control group. The selected participants were subjected to history taking, mammogram to detect BAC and biochemical assessment of lipid profile, Serum creatinine, Mg, P, Ca, PTH and FGF23. Results: the presence of BAC in about $81.8 \%$ of stage 4 CKD patients compared with $50 \%$ in stage 3 CKD, also in the majority of stage 4 CKD patients had high FGF-23. Receiver operator characteristic (ROC) curve analysis showed serum FGF-23 as a potential predictor of BAC (AUC $=0.874)$ in CKD patients at the cut-off point of $77.5 \mathrm{ng} / \mathrm{ml}$ (sensitivity $78 \%$, specificity $76 \%$ ). Conclusion: Although it is difficult to determine the definite stage at which the risk of VC begins but, in our study, it began late in stage 2 CKD, gradually increased prevalence through stage 3 , and became significantly higher in stage 4. FGF23 could be a good predictor of BAC in CKD
\end{abstract}

Keywords: vascular calcification, Fibroblast growth factor-23, stages, kidney disease

\section{Introduction}

Vascular calcification (VC) plays a major role in cardiovascular disease (CVD), which is one of the main causes of mortality in patients with chronic kidney disease (CKD). VC is a complex process, involving not only simple precipitation of supersaturated phosphorus $(\mathrm{P})$ and calcium (Ca) hydroxyapatite crystals in the extracellular milieu (mineral step), but also cellular step involving apoptosis, osteochondrogenic differentiation, and elastin degradation. Calcification of the vascular tree is common in physiologic and pathologic conditions, i.e., aging, diabetes mellitus (DM), dyslipidemia, genetic diseases, and diseases with disturbances

\footnotetext{
*Corresponding Author: drhamdyomar@yahoo.com
} 
of Ca metabolism. CKD is one of the main conditions associated with $\mathrm{VC}^{(1)}$. Many risk factors are involved in the pathogenesis of $\mathrm{VC}$ but the main is an imbalance between promoters and inhibitors of VC. ${ }^{(2)}$. VC can be presented by different clinical involvements as medial arterial calcification (MAC), intimal calcification, cardiac valvular calcification, and uremic calcific arteriopathy (UCA)(3) MAC is common in advanced kidney disease, which locates mainly in the tunica media that contains vascular smooth muscle cells (VSMC) and elastic tissues but its impact on CVD is uncertain because imaging techniques used nowadays cannot reliably distinguish it from atherosclerotic calcification ${ }^{(4)}$. The prevalence of VC increases steadily throughout the stages of CKD reaching its peak in CKD Stage 5 patients(5). The prevalence of breast arterial calcification (BAC) was not increased in patients with stage $3 C K D$, suggesting that the risk of MAC develops later in CKD and that preventative strategies may not be necessary for early $\mathrm{CKD}^{(6)}$. VC is currently considered as a cardiovascular risk marker; the presence of $\mathrm{VC}$ has been associated with a several-fold increase in the risk of morbidity and mortality in both the general population and CKD Stage 5 patients $(7)$. Although VC can be assessed by various methods, such as Doppler Ultrasonography, simple radiology, Echocardiography and computed tomography $(\mathrm{CT})$, detection of BAC by a mammogram is a useful radiological method as it indicates tunica media calcification commonly encountered in $\mathrm{CKD}^{(6,8)}$. Fibroblast growth factor-23 (FGF23) is synthesized and secreted by osteoblasts and osteocytes. The role of FGF-23 is as a regulator of circulating serum $P$ and vitamin $D^{(9)}$. During the early stages of CKD, there is an increase in the levels of $\mathrm{FGF}_{23}$ to keep serum $\mathrm{P}$ within the normal range ${ }^{(10)}$. In CKD patients, the plasma level of FGF23 is higher than the upper limit of the normal range in healthy individuals and it was found to be associated with increased severity and progression of aortic calcification and peripheral arterial calcification and correlated with cardiovascular events and death $(5,11)$. There is controversy regarding the role of FGF23; whether it is a contributor to VC or inhibitor(10). Overall, many factors are leading to VC in CKD patients, and our study aimed at investigating the association of FGF-23 serum levels and early detection of BAC and identifying the frequency of higher levels of FGF-23 in different stages of CKD which can be counted as indicators of systemic VC in CKD patients.

\section{Patients and Methods}

The study is a case-control study targeting CKD women divided into 3 groups (stages 2, 3\& 4) who attended nephrology \& Internal medicine outpatient clinics and/or were admitted to the inpatient ward at Suez Canal University Hospital. The $4^{\text {th }}$ group is the control group including women with normal kidney function, aged between 18- 60 years old (22 women/ group). The patients were divided into groups according to the stage of CKD (according to glomerular filtration rate (GFR)) and patients were allocated to one of the four groups: Group A: stage 2 CKD women (GFR (60-89 mL/min/1.73 $\mathrm{m}^{2}$ ), Group B: stage 3 CKD women GFR (30-59 $\left.\mathrm{mL} / \mathrm{min} / 1.73 \mathrm{~m}^{2}\right)$, Group C: stage 4 CKD women GFR (15-29 mL/min/1.73 m²), Group D: women without kidney disease (control group) (Absence of CKD was defined as a serum creatinine value $<1.0 \mathrm{mg} / \mathrm{dl}$ obtained within 6 months before the mammogram). The selected participants were subjected to history taking, mammogram, and biochemical assessment. 
Biochemical laboratory tests

Lipid profile (including LDL, VLDL, HDL, Cholesterol and triglycerides using diagnostic kits provided from (Spin-react, Spain), following the instructions of the manufacturers and dyslipidemia will be defined according to the guidelines of the National Cholesterol Education Program $^{(12)}$, Serum creatinine $(\mathrm{Cr}), \mathrm{Mg}, \mathrm{Ph}, \mathrm{Ca}$, and PTH (Human Parathyroid Hormone (PTH) ELISA Kit, Abcam) and FGF-23 (Human FGF23 ELISA Kit, Abcam) were done to all the studied participants.

\section{Mammography}

Mammograms (by: GE 600 (GE health care, BUC, France) were retrieved in digital images. Screening of mammograms for BAC was done by visual inspection by double readers and was restricted to the determination of whether BAC was present or absent. BAC appears as thin, parallel, linear densities along the margins of blood vessels and is easily distinguished from other calcifications, which appear as spots or single, thicker linear densities. Mammography detected MAC, based on their histology and vessel size, BAC is a specific and useful marker of MAC in CKD, and its prevalence is markedly increased in advanced $\mathrm{CKD}^{(13)}$.

\section{Ethical Consideration}

The study was approved by the Ethical Committee of the faculty of Medicine, Suez Canal University under reference number 3091\#.

\section{Statistical analysis}

Data were managed using Statistical Package of Social Sciences (SPSS) software program version 25. Statistical significance tests were used and the probability value ( $P$-value) of $\leq 0.05$ was considered statistically significant (At 95\% level of confidence). Descriptive statistics were presented as (Means \pm Standard Deviation) for quantitative variables and as (Percent) for qualitative variables. Nonparametric data were presented as median and interquartile range and analyzed using the Mann-Whitney $U$ test or Kruskal Wallis test. Student t-test was used to test the significance of difference for quantitative variables. The correlation was assessed using Spearman's correlation. Receiver operator characteristic (ROC) curves were constructed to assess the area under the curve (AUC). Odds ratios (OR) and $95 \%$ confidence intervals $(\mathrm{Cl})$ were presented.

\section{Results}

Demographic and clinical data of the study population are presented in Table (1). The age ranged from 19 to 60 years with a significant difference in age between all groups regarding hypertension, dyslipidemia, BAC, and lipid \& metabolic profiles, while non-significant difference regarding the use of anti-coagulants was found. It was found that stage 4 CKD patients had the highest prevalence of age, presence of hypertension, and dyslipidemia. Regarding BAC distribution, we found a statistically significant difference between study groups. $81.8 \%$ of stage 4 CKD patients were found to have BAC, $36.4 \%$ in stage 3 , and $22.7 \%$ in stage 2 (figure1). BAC was found in the majority of CKD stage 4 patients with abnormal lipid profile parameters, hypermagnesemia, hypocalcemia, hyperparathyroidism and increased FGF-23 levels (502.27 $\pm 130.45 \mathrm{ng} / \mathrm{ml}$ ) (Table 2). The mean serum level of FGF-23 in the positive BAC patients was $307.88 \pm 112.32 \mathrm{ng} / \mathrm{ml}$ and was highly elevated than negative $B A C$ patients $84.96 \pm 45.12 \mathrm{ng} / \mathrm{ml}(P=<0.001)$ (figure $2 A)$. 


\begin{tabular}{|c|c|c|c|c|c|c|}
\hline \multicolumn{7}{|c|}{ Table 1: Demographic and clinical data of the study population } \\
\hline \multicolumn{2}{|c|}{ Group } & Stage 2 & Stage 3 & Stage 4 & Control & \multirow{2}{*}{ p-valt } \\
\hline Variables & Attributes & $\mathrm{n}(\%)$ & $\mathrm{n}(\%)$ & $\mathrm{n}(\%)$ & $\mathrm{n}(\%)$ & \\
\hline Hypertension@ & $\begin{array}{l}\text { No } 19(21.6 \%) \\
\text { Yes } 69(78.4 \%)\end{array}$ & $\begin{array}{l}3(13.6) \\
19(86.4)\end{array}$ & $\begin{array}{l}6(27.3) \\
16(72.7)\end{array}$ & $\begin{array}{l}0(0) \\
22(100)\end{array}$ & $\begin{array}{l}10(45.5) \\
12(54.5)\end{array}$ & $0.002 *$ \\
\hline Dyslipidemia@ & $\begin{array}{l}\text { No } 45(51.1 \%) \\
\text { Yes } 43(48.9)\end{array}$ & $\begin{array}{l}15(68.2) \\
7(31.8)\end{array}$ & $\begin{array}{l}11(50) \\
11(50)\end{array}$ & $\begin{array}{l}4(18.2) \\
18(81.8)\end{array}$ & $\begin{array}{l}15(68.2) \\
7(31.8)\end{array}$ & $0.002 *$ \\
\hline $\begin{array}{l}\text { Use of anti- } \\
\text { coagulation }\end{array}$ & $\begin{array}{l}\text { No } 83(94.3 \%) \\
\text { Yes } 5(5.7 \%)\end{array}$ & $\begin{array}{l}21(95.5) \\
1(4.5)\end{array}$ & $\begin{array}{l}22(100) \\
0(0)\end{array}$ & $\begin{array}{l}20(90.9) \\
2(9.1)\end{array}$ & $\begin{array}{l}20(90.9) \\
2(9.1)\end{array}$ & 0.506 \\
\hline $\begin{array}{l}\text { Breast arterial } \\
\text { calcification@ }\end{array}$ & $\begin{array}{l}\text { No } 56(63.6 \%) \\
\text { Yes } 32(36.4 \%)\end{array}$ & $\begin{array}{l}17(77.3) \\
5(22.7)\end{array}$ & $\begin{array}{l}14(63.6) \\
8(36.4)\end{array}$ & $\begin{array}{r}4(18.2) \\
18(81.8)\end{array}$ & $\begin{array}{r}21(95.5) \\
1(4.5)\end{array}$ & $<0.001 *$ \\
\hline \multirow[t]{2}{*}{ Age $^{\xi}$} & $\begin{array}{c}\text { Mean } \pm \text { SD } \\
39.98+10.82\end{array}$ & $41.81 \pm 9.53$ & $36.50 \pm 11.52$ & $47.86 \pm 9.54$ & $33.77 \pm 7.01$ & $<0.001^{*}$ \\
\hline & Range & \multicolumn{5}{|c|}{$41(60-19)$} \\
\hline
\end{tabular}

@=Data are presented as N (\%) calculated by Chi-square test, $\$=$ data are presented as Mean + SD calculated by ANOVA test; , * Significant difference ( $P$-value $<0.05$

Additionally, the CKD patients at stage 4 with positive $B A C$ have a significantly high level of serum FGF-23 (486.11 $\pm 118.57 \mathrm{ng} / \mathrm{ml})$ when compared to patients with different CKD stages (figure 2B). Meanwhile, there was a positive correlation between serum levels of FGF-23 and positive BAC in the studied participants $(r=0.616, P=<0.001)$.
Receiver operator characteristic (ROC) curve analysis was performed and showed serum FGF-23 as a potential predictor of breast arterial calcification $(A \cup C=0.874)$ in CKD patients at the cut-off point of $77.5 \mathrm{ng} / \mathrm{ml}$ with a sensitivity of $78 \%$ and a $76 \%$ of specificity (figure 3 ).

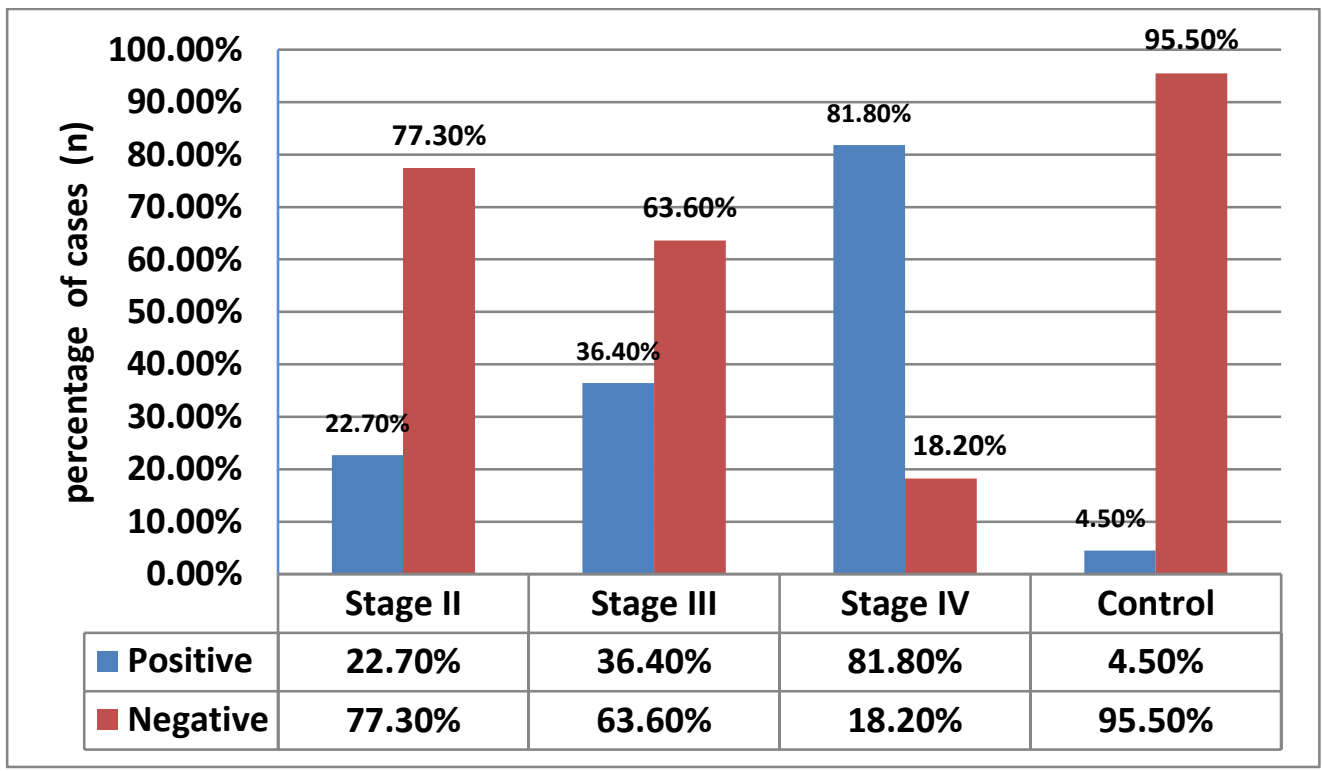

Figure 1: Frequency of breast arterial calcification among the study population 


\begin{tabular}{|c|c|c|c|c|c|}
\hline Group & Stage 2 (22) & Stage $3(22)$ & Stage $4(22)$ & Control (22) & -value \\
\hline Variables & $\mathrm{N}(\%)$ & $\mathrm{N}(\%)$ & $\mathrm{N}(\%)$ & $\mathrm{N}(\%)$ & \\
\hline $\begin{array}{l}\text { HDL }(\mathrm{mg} / \mathrm{dl}) \\
\text { Normal } \\
\text { Low } \\
\text { Mean } \pm \text { SD }\end{array}$ & $\begin{array}{c}15(68.2) \\
7(31.8) \\
57.50 \pm 17.44\end{array}$ & $\begin{array}{c}12(54.5) \\
10(45.5) \\
55.22 \pm 22.75\end{array}$ & $\begin{array}{c}4(18.2) \\
18(81.8) \\
37.27 \pm 16.95\end{array}$ & $\begin{array}{c}15(68.2) \\
7(31.8) \\
57.68 \pm 18.11\end{array}$ & $\begin{array}{l}0.002 * \\
0.001 *\end{array}$ \\
\hline $\begin{array}{l}\text { LDL }(\mathrm{mg} / \mathrm{dl}) \\
\text { Normal } \\
\text { Abnormal } \\
\text { Mean } \pm \text { SD }\end{array}$ & $\begin{array}{c}15(68.2) \\
7(31.8) \\
98.86 \pm 37.28\end{array}$ & $\begin{array}{c}11(50) \\
11(50) \\
118.40 \pm 35.70\end{array}$ & $\begin{array}{c}4(18.2) \\
18(81.8) \\
150.68 \pm 34.16\end{array}$ & $\begin{array}{c}15(68.2) \\
7(31.8) \\
107.95 \pm 39.17\end{array}$ & $\begin{array}{l}0.002 * \\
<0.001 *\end{array}$ \\
\hline $\begin{array}{l}\text { VLDL }(\mathrm{mg} / \mathrm{dl}) \\
\text { Normal } \\
\text { Abnormal } \\
\text { Mean } \pm S D\end{array}$ & $\begin{array}{c}15(68.2) \\
7(31.8) \\
38.18 \pm 20.73\end{array}$ & $\begin{array}{c}10(45.5) \\
12(54.5) \\
37.27 \pm 15.40\end{array}$ & $\begin{array}{c}4(18.2) \\
18(81.8) \\
67.27 \pm 24.57\end{array}$ & $\begin{array}{c}15(68.2) \\
7(31.8) \\
35.09 \pm 22.52\end{array}$ & $\begin{array}{l}0.002 * \\
<0.001 *\end{array}$ \\
\hline $\begin{array}{l}\text { Triglyceride }(\mathbf{m g} / \mathrm{dl}) \\
\text { Normal } \\
\text { Abnormal } \\
\text { Mean } \pm \text { SD }\end{array}$ & $\begin{array}{c}15(68.2) \\
7(31.8) \\
190.90 \pm 40.82\end{array}$ & $\begin{array}{c}10(45.5) \\
12(54.5) \\
186.36 \pm 77.04\end{array}$ & $\begin{array}{c}4(18.2) \\
18(81.8) \\
336.36 \pm 122.85\end{array}$ & $\begin{array}{c}15(68.2) \\
7(31.8) \\
175.45 \pm 112.62\end{array}$ & $\begin{array}{l}0.002^{*} \\
<0.001 *\end{array}$ \\
\hline $\begin{array}{l}\text { Cholesterol(mg/dl) } \\
\text { Normal } \\
\text { Abnormal } \\
\text { Mean } \pm \text { SD }\end{array}$ & $\begin{array}{c}15(68.2) \\
7(31.8) \\
194.54 \pm 40.82\end{array}$ & $\begin{array}{c}9(40.9) \\
13(59.1) \\
210.22 \pm 33.00\end{array}$ & $\begin{array}{c}4(18.2) \\
18(81.8) \\
256.59 \pm 36.85\end{array}$ & $\begin{array}{c}15(68.2) \\
7(31.8) \\
200.50 \pm 42.18\end{array}$ & $\begin{array}{l}0.001^{*} \\
<0.001 *\end{array}$ \\
\hline $\begin{array}{l}\text { Creatinine }(\mathbf{m g} / \mathrm{dl}) \\
\text { Mean } \pm \text { SD }\end{array}$ & $1.14 \pm 0.95$ & $2.10 \pm 0.24$ & $3.13 \pm 0.53$ & $0.67 \pm 0.98$ & $<0.001 *$ \\
\hline eGFR Mean \pm SD & $67.95 \pm 7.25$ & $34.85 \pm 4.16$ & $21.06 \pm 3.89$ & 134.17 & $001 *$ \\
\hline $\begin{array}{l}M g(m g / d l) \\
\text { Normal } \\
\text { High } \\
\text { Mean } \pm S D\end{array}$ & $\begin{array}{c}22(100) \\
0(0) \\
1.86 \pm 0.26\end{array}$ & $\begin{array}{l}15(68.2) \\
7(31.8) \\
2.09 \pm 044\end{array}$ & $\begin{array}{c}3(13.6) \\
19(86.4) \\
3.14 \pm 0.61\end{array}$ & $\begin{array}{c}22(100) \\
0(0) \\
1.91 \pm 0.23\end{array}$ & $\begin{array}{l}<0.001 * \\
<0.001 *\end{array}$ \\
\hline $\begin{array}{l}\text { Phosphorus }(\mathrm{mg} / \mathrm{dl}) \\
\text { Normal } \\
\text { High } \\
\text { Mean } \pm \text { SD }\end{array}$ & $\begin{array}{c}19(86.4) \\
3(13.6) \\
3.85 \pm 0.53\end{array}$ & $\begin{array}{l}13(59.1) \\
9(40.9) \\
4.38+0.34\end{array}$ & $\begin{array}{c}4(18.2) \\
18(81.8) \\
5.61 \pm 1.01\end{array}$ & $\begin{array}{c}22(100) \\
0(0) \\
3.69 \pm 0.38\end{array}$ & $\begin{array}{c}<0.001 * \\
0.138\end{array}$ \\
\hline $\begin{array}{l}\text { Calcium }(\mathrm{mg} / \mathrm{dl}) \\
\text { Normal } \\
\text { Low } \\
\text { Mean } \pm \text { SD }\end{array}$ & $\begin{array}{c}15(68.2) \\
7(31.8) \\
9.29 \pm 0.57\end{array}$ & $\begin{array}{c}13(59.1) \\
9(40.9) \\
8.67 \pm 0.45\end{array}$ & $\begin{array}{c}0(0) \\
22(100) \\
7.56 \pm 0.64\end{array}$ & $\begin{array}{c}22(100) \\
0(0) \\
9.72 \pm 0.39\end{array}$ & $\begin{array}{l}<0.001^{*} \\
<0.001^{*}\end{array}$ \\
\hline $\begin{array}{l}\text { PTH }(\mathrm{pg} / \mathrm{ml}) \\
\text { Normal } \\
\text { High } \\
\text { Mean } \pm \text { SD }\end{array}$ & $\begin{array}{c}17(77.3) \\
5(22.7) \\
65.23 \pm 11.28\end{array}$ & $\begin{array}{l}13(59.1) \\
9(40.9) \\
68.41 \pm 8.2 \\
\end{array}$ & $\begin{array}{c}0(0) \\
22(100) \\
125.68 \pm 33.82\end{array}$ & $\begin{array}{c}22(100) \\
0(0) \\
33.41 \pm 9.56\end{array}$ & $\begin{array}{l}<0.001 * \\
<0.001 *\end{array}$ \\
\hline $\begin{array}{l}\text { FGF-23 }(\mathrm{ng} / \mathrm{ml}) \\
\text { Normal } \\
\text { High } \\
\text { Mean } \pm \text { SD }\end{array}$ & $\begin{array}{c}17(77.3) \\
5(22.7) \\
41.55 \pm 9.73\end{array}$ & $\begin{array}{c}1(4 \cdot 5) \\
21(95 \cdot 5) \\
93.64 \pm 15.75 \\
\end{array}$ & $\begin{array}{c}0(0) \\
22(100) \\
502.27 \pm 130.45\end{array}$ & $\begin{array}{c}22(100) \\
0(0) \\
26.64 \pm 9.26\end{array}$ & $\begin{array}{l}<0.001 * \\
<0.001 *\end{array}$ \\
\hline
\end{tabular}

Data are presented as N (\%) * Significant difference (P-value $<0.05)$, Mean \pm SD were determined using Kruskal-Wallis test and ANOVA 
Mostly, all the variables except for the use of anticoagulation had statistical significance regarding the presence of $B A C$ in mammograms and this was detected by using a simple regression model to identify the risk factors of BAC (table $3 \mathrm{~A}, \mathrm{~B}$ ). Each row represents a separate model of prediction. Each model means that for every change of beta $(\beta)$ arterial calcifi- cation occurs/happens. All these models consider calcification as a binary (yes/no) variable, e.g.: BAC occurs starting stage 2.183 (if stages can be arbitrarily considered as a continuous variable from 0 (control) to 4). The analyses between variables and BAC were done using a oneto-one relationship using univariate analyses.

\begin{tabular}{|c|l|c|c|c|c|}
\hline \multicolumn{6}{|c|}{ Table 3: (A) Simple logistic regression models for BAC (Qualitative variables) } \\
\hline Model & Variables & B & p-value & OR & $95 \%$ CI for OR \\
\hline 1 & Hypertension & 2.687 & $<0.05^{*}$ & 14.684 & $(1.855-116.229)$ \\
\hline 2 & Dyslipidemia & 4.733 & $<0.05^{*}$ & 113.667 & $(14.043-920.019)$ \\
\hline 3 & Use of anti-coagulation & 2.061 & 0.071 & 7.857 & $(0.838-73.661)$ \\
\hline 4 & Staging & 1.183 & $<0.05^{*}$ & 3.263 & $(1.88-5.664)$ \\
\hline
\end{tabular}

\section{Discussion}

The presence of $\mathrm{VC}$ has been associated with a several-fold increase in the risk of morbidity and mortality in both the general population and CKD patients which are considered as a cardiovascular risk marker ${ }^{(4)}$. The prevalence of $\mathrm{VC}$ increases steadily through the stages of CKD peaking in CKD Stage 5D patients so our study aims at early detection of $B A C$ in different stages of CKD (stages 2, 3\& 4) patients. In this study, we found that there were statistically significant differences between groups regarding the high levels of serum FGF-23 and the presence of BAC among CKD patients specially stage 4 CKD patients.

\begin{tabular}{|c|c|c|c|c|c|}
\hline \multicolumn{7}{|c|}{ Table (3) (B): Simple logistic regression models for BAC } \\
(Quantitative variables) \\
\hline Model & Variables & B & p-value & OR & 95\% CI for OR \\
\hline 1 & Age & 0.253 & $<0.05^{*}$ & 1.289 & $(1.164-1.427)$ \\
\hline 2 & HDL & -0.125 & $<0.05^{*}$ & 0.883 & $(0.837-0.931)$ \\
\hline 3 & LDL & 0.058 & $<0.05^{*}$ & 1.060 & $(1.036-1.084)$ \\
\hline 4 & VLDL & 0.100 & $<0.05^{*}$ & 1.105 & $(1.065-1.147)$ \\
\hline 5 & Triglycerides & 0.020 & $<0.05^{*}$ & 1.020 & $(1.013-1.028)$ \\
\hline 6 & Cholesterol & 0.054 & $<0.05^{*}$ & 1.056 & $(1.034-1.078)$ \\
\hline 7 & Creatinine & 1.287 & $<0.05^{*}$ & 3.622 & $(2.019-6.495)$ \\
\hline 8 & eGFR & -0.047 & $<0.05^{*}$ & 0.954 & $(0.932-0.977)$ \\
\hline 9 & Magnesium & 1.791 & $<0.05^{*}$ & 5.996 & $(2.436-14.758)$ \\
\hline 10 & Phosphorus & 1.814 & $<0.05^{*}$ & 6.133 & $(2.599-14.47)$ \\
\hline 11 & Calcium & -1.772 & $<0.05^{*}$ & 0.170 & $(0.079-0.365)$ \\
\hline 12 & Parathormone & 0.043 & $<0.05^{*}$ & 1.044 & $(1.023-1.065)$ \\
\hline 13 & FGF23 & 0.006 & $<0.05^{*}$ & 1.006 & $(1.003-1.009)$ \\
\hline
\end{tabular}


BAC represents $22.7 \%$ of stage $2,36.4 \%$ of stage 3 , and $81.8 \%$ of stage 4 . The age ranged from 19 to 60 years with a significant difference in age between all groups. Although CKD is proved to be a risk factor for VC, it is difficult to determine at which stage this risk begins so it is better to assess the progression rather than quantity, which can be affected by the duration of CKD and the presence of many other risk factors like hypertension, dyslipidemia and electrolyte disturbance.
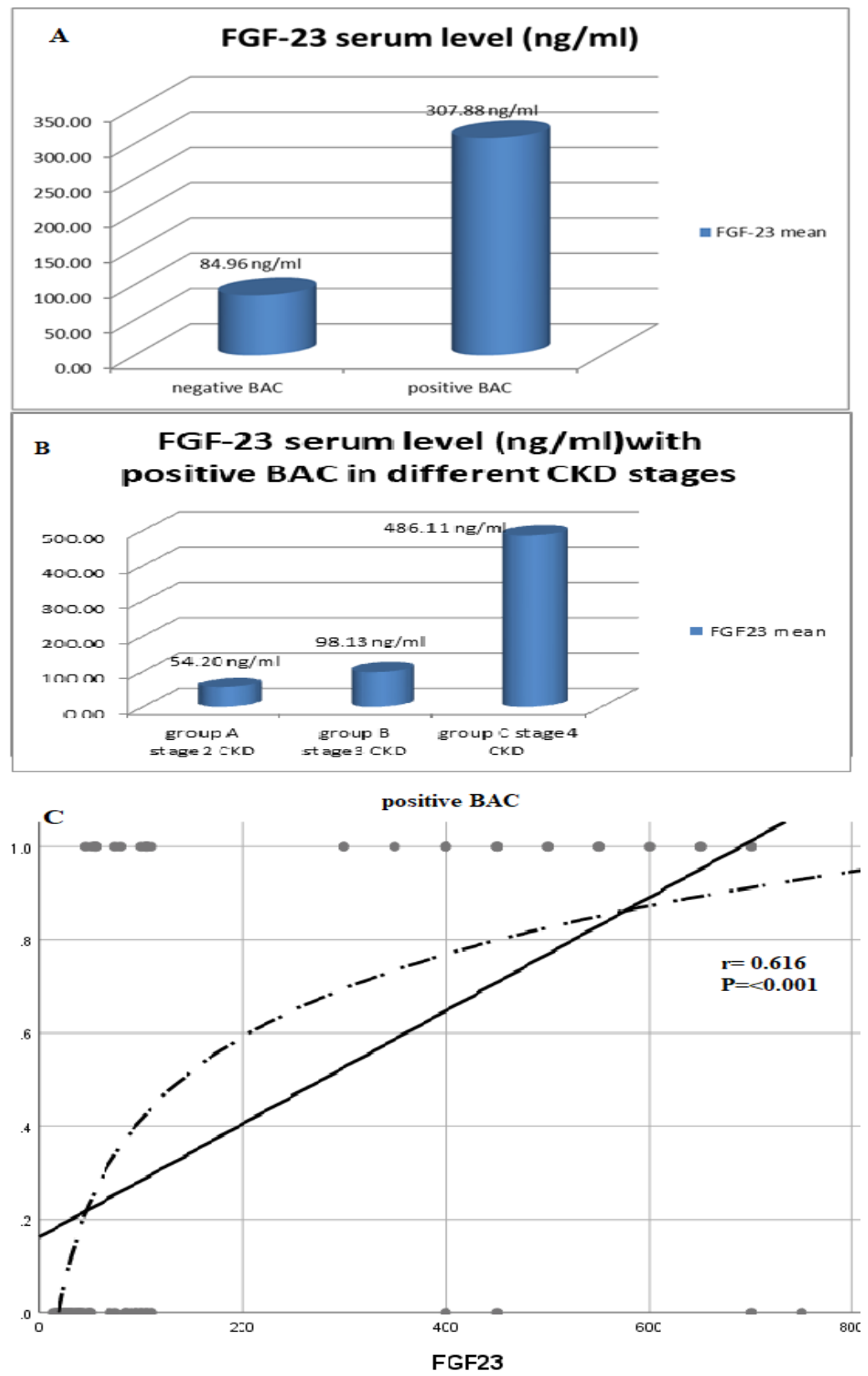

Figure 2: Fibroblast growth factor-23(FGF-23) serum levels in the studied population A: comparison of FGF-23 serum means levels in patients with negative breast arterial calcification (BAC) and positive $B A C$ in the studied population, B: distribution of FGF-23 serum levels in positive BAC patients of the different groups. C: correlation of mean serum levels of $F G F-23$ and positive $B A C$ in the studied groups $(r=0.616, P=<0.001)$. 
Hassan et al. (2012) found that 25\% of stage $3,40 \%$ of stage 4 , and $60 \%$ of stage 5 CKD patients had BAC. Although the prevalence of CKD increases with age and age is used to calculate eGFR and therefore to assign CKD stage, this cannot explain the increased prevalence of BAC in
$\mathrm{CKD}^{(2)}$. While others found that $50 \%$ of stage $3,83 \%$ of stage 4 , and $91 \%$ of stage 5 CKD patients had abdominal aortic calcification (by $\mathrm{CT}$ without contrast ${ }^{(14)}$. Manzoor et al. (2018) reported an increase in the prevalence of $B A C$ in women with stage 4 or 5 CKD, but not CKD $3^{(4)}$.

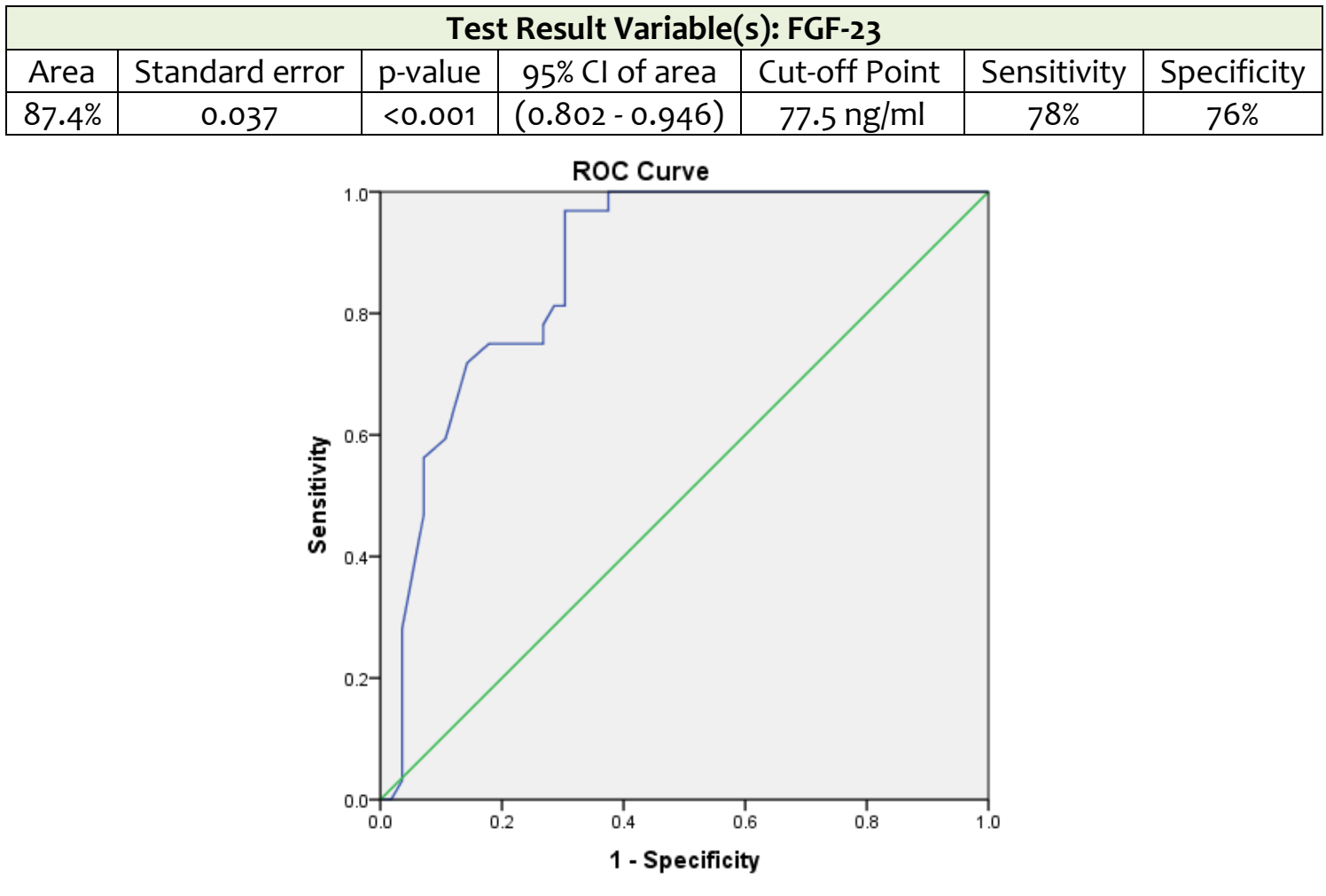

Figure3: Receiver operator characteristic (ROC) curve analysis Serum FGF-23 as a potential predictor of vascular calcification at the cut-off point of $77.5 \mathrm{ng} / \mathrm{ml}$ with a sensitivity of $78 \%$ and a specificity of $76 \%$.

Also, Górriz, et al. (2015), in their study showed an increase in calcification of hand arteries in stages 4 and 5 compared to stage 3, however, the latter study did not examine earlier stages(15). We evaluated the presence of $\mathrm{VC}$ by using mammograms to detect BAC and we found that there were significant relationships regarding the presence of BAC in hypertensive and dyslipidemic patients in different stages of CKD and control groups as higher frequency of $B A C$ in hypertensive and dyslipidemic patients with a gradual increase in the number of patients with $B A C$ with the progression of CKD staging. There was no significant relationship between groups regarding the use of anticoagulation and the presence of BAC and this may be due to the small number of included patients that were kept on oral anticoagulants during or years before our study. VC with the use of oral anticoagulants is usually dependent on dose and duration of administration ${ }^{(16)}$. Also, we 
found statistically significant differences between study groups regarding the presence of BAC among study groups subdivided by abnormal lipid profile constituents (low HDL, high LDL, high VLDL, high triglyceride, and high cholesterol). Biyik, et al. in 2016 found that there was no significant correlation between the presence of VC and lipid levels and systolic and/or diastolic blood pressure $^{(17)}$. While S. McLenachan and his colleagues found that 36\% of hypertensive patients in their study had BAC ${ }^{(18)}$. Yıldız, et al. (2016) found that LDL and non-HDL levels were significantly higher, HDL levels were significantly lower in the CKD group compared to the control group and a significant positive correlation was found between BAC and lipid indices with both LDL and non-HDL were positively correlated whereas HDL was negatively correlated with the $\mathrm{BAC}^{(19)}$.

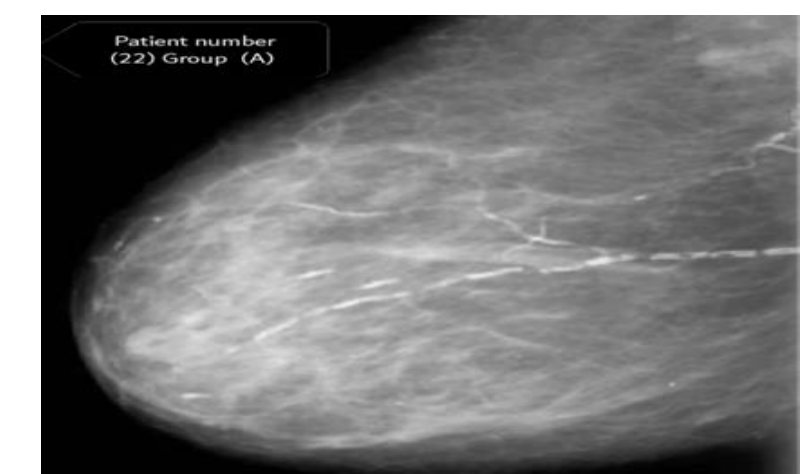

Figure (4A): $B A C$ inpatient within-group $(A)$ This figure shows the presence of punctuating $V C s$, grade (2) BAC on the four-point scale in stage 2 CKD patients.

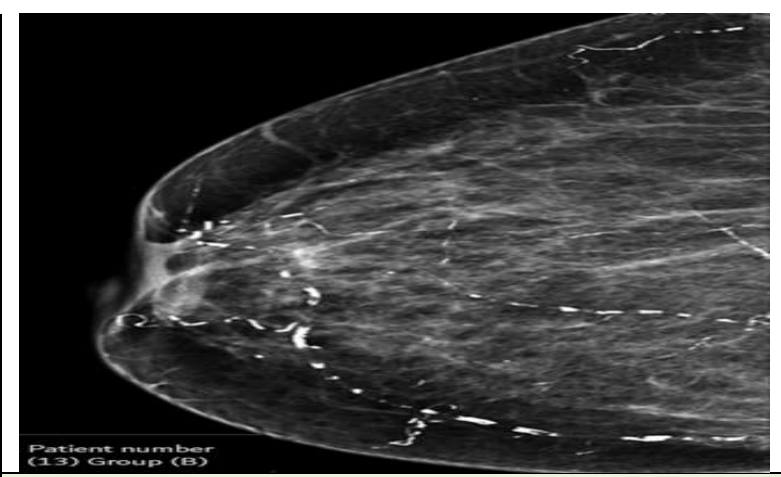

Figure (4B): $B A C$ in a patient within-group (B) This figure shows the presence of punctuating VCs, grade (2) BAC on the fourpoint scale in stage 3 CKD patients.

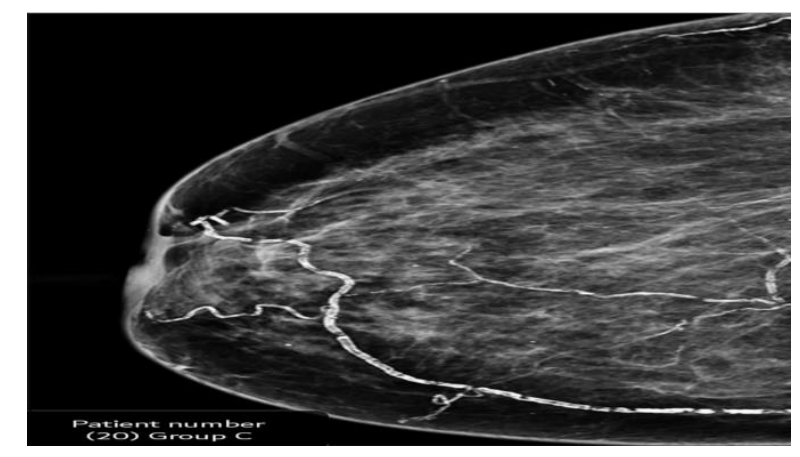

Figure (4C): $B A C$ in a patient within-group (C) This figure shows the presence of coarse (tram track) VCs affecting three vessels, grade (4) $B A C$ on the four-point scale in stage 4 CKD.

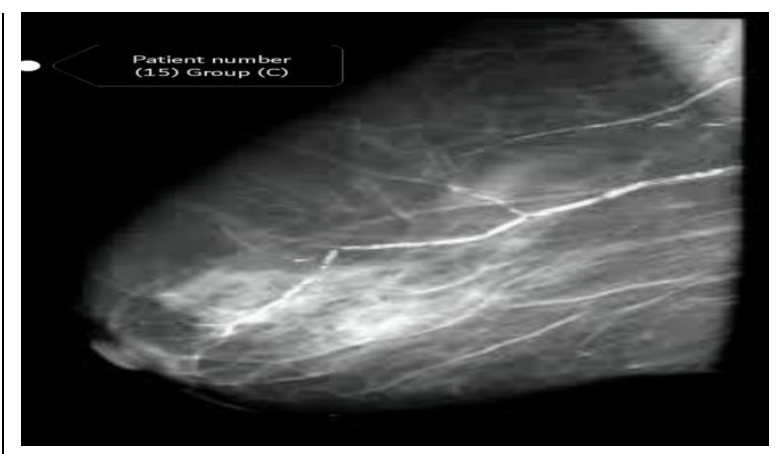

Figure (4D): BAC in a patient within-group (C) This figure shows the presence of coarse (tram track) VCs affecting one vessel, grade (3) BAC on the four-point scale stage 4 CKD patient.

\section{Figure 4: The radiological presentation of BAC in different stages of CKD}

Tantisattamo, et al. in 2015 found that the prevalence of BAC is increased in women with current or past warfarin use indepen- dent of other risk factors and conditions predating warfarin use. This effect appears to be cumulative and may be irre- 
versible(20). The use of warfarin is associated with an increase in systemic calcification, including the coronaries and peripheral vasculature. This increase in VC is due to inhibition of the enzyme MGP that is a vitamin K-dependent protein, resulting in the accumulation of undercarboxylated protein that lacks calcification inhibitory capacity and, consequently, promotes vascular mineralization ${ }^{(21)}$. We found that BAC starts at stage 2.183 (if stages can be arbitrarily considered as a continuous variable from o(control) to 4). Biyik, et al. used a Univariate logistic regression analysis that showed that VC presence (detected by Abdominal aortic calcification (AAC)) was correlated with age in the predialysis group. There was no significant correlation between VC and smoking, corrected serum $\mathrm{Ca}$ and lipid levels, proteinuria, and systolic or diastolic blood pressure. There was a positive association between the VC presence and history of $D M$, serum $P, C R P$, and history of CVD. There was also a significant relationship between the AAC presence and eGFR, albumin. (17) Dhakshinamoorthy, et al. in their Univariate logistic regression analysis observed that the significant risk factors for the presence of VC were age and high sensitive CRP. There was a non-significant association between $\mathrm{VC}$ and serum $\mathrm{Ca}$ levels(22). Elevated phosphate, calcium, PTH, and FGF23 levels are all associated with vascular calcification in patients with CKD and may directly promote calcification $^{(10)}$. The biochemical analysis in this study showed significant differences in terms of all lipid profile parameters, serum creatinine, eGFR, and serum $\mathrm{Mg}$, serum $\mathrm{Ca}$, serum $\mathrm{P}, \mathrm{PTH}$, and FGF23. At Stage 4 CKD, patients had the highest prevalence of disturbance of lipid profile, hypr-magnesemia, hypocalcemia, hyper-phosphatemia, and increased both PTH \& FGF23. Hassan, et al. at 2012 found that Whereas levels of PTH and FGF-23 are elevated in stage $3 \mathrm{CKD}$, the prevalence of hyperphosphatemia is still low but increases sharply in stage 4 CKD, corresponding to the significant increase in $\mathrm{BAC}^{(23)}$ While Bureo and his colleagues concluded in their study that hypocalcemia was found in $20.9 \%$ of patients with stage 3 CKD and $30.3 \%$ of stage 4 patients. Median PTH in stage 3 patients was $86 \mathrm{pg} / \mathrm{mL}$; $62.9 \%$ of these patients had PTH levels $\geq 70$ $\mathrm{pg} / \mathrm{mL}$, and $32.7 \%$ values $\geq 110 \mathrm{pg} / \mathrm{mL}$. In stage 4 patients, the median PTH level was $120 \mathrm{pg} / \mathrm{mL}$. Of these, $77.9 \%$ had PTH $\geq 70$ $\mathrm{pg} / \mathrm{mL}$, and $54.1 \% \mathrm{PTH} \geq 110 \mathrm{pg} / \mathrm{mL}^{(24)}$. Another study detected that women with higher serum FGF-23 had a significantly lower education level, higher serum creatinine, lower eGFR, lower HDL cholesterol, higher PTH, lower 1,25( $\mathrm{OH})_{2} \mathrm{D}$, higher $25(\mathrm{OH}) \mathrm{D}$, higher calcium, higher phosphate; higher prevalence of hypertension, coronary artery disease, congestive heart failure, and CKD; and lower prevalence of the chronic obstructive pulmonary disease. ${ }^{(25)}$ FGF-23 concentrations increase with declining renal function among patients with CKD. (26). Also, we found statistically significant differences and a positive correlation between study groups regarding the presence of $B A C$ and high FGF23. Using the ROC curve, we found that the cut-off point for FGF-23 to predict BAC is $77.5 \mathrm{ng} / \mathrm{ml}$ and this was statistically significant (the sensitivity $78 \%$, the specificity of $76 \%$ ).

\section{Conclusion}

We found that VC begins late in stage 2 CKD, with a gradually increased prevalence through stage 3, and becomes significantly higher in stage 4 . These results suggest that preventive strategies may need to begin as early as stage 2 CKD. FGF-23 could 
be a good predictor of BAC in CKD and a biomarker of early cardiovascular events.

\section{References}

1. Amann K. Media calcification and intima calcification are distinct entities in chronic kidney disease. Clin J Am Soc Nephrol. 2008;3(6):1599-605.

2. Hassan NA, D'Orsi ET, D'Orsi $C J$, et al. The risk for medial arterial calcification in CKD. Clin J Am Soc Nephrol. 2012; 7(2):275-9.

3. Román-García P, Rodríguez-García M, Cabezas-Rodríguez I, et al. Vascular calcification in patients with chronic kidney disease: types, clinical impact and pathogenesis. Medical principles practice. 2011;20(3):203-12.

4. Manzoor S, Ahmed S, Ali A, et al. Progression of Medial Arterial Calcification in CKD. Kidney Int Rep. 2018; 3 (6):1328-35.

5. Liabeuf S, Okazaki H, Desjardins L, et al. Vascular calcification in chronic kidney disease: are biomarkers useful for probing the pathobiology and the health risks of this process in the clinical scenario? Nephrol Dial Transplant. 2014; 29(7):1275-84.

6. Duhn V, D'Orsi ET, Johnson $S$, et al. Breast arterial calcification: a marker of medial vascular calcification in chronic kidney disease. Clin J Am Soc Nephrol. 2011;6(2):377-82.

7. Rennenberg R, Kessels A, Schurgers L, et al. Vascular calcifications as a marker of increased cardiovascular risk: a meta-analysis. Vascular health risk management. 2009;5:185.

8. Sharaf El Din UA, Salem MM, Abdulazim DO. Vascular calcification: When should we interfere in chronic kidney disease patients and how? World J Nephrol. 2016;5(5):398-417.

9. Tamei N, Ogawa $T$, Ishida $H$, Serum fibroblast growth factor-23 levels and progression of aortic arch calcification in non-diabetic patients on chronic hemodialysis. J Atheroscler Thromb. 2011;18(3):217-23.

10. Palit S, Kendrick J. Vascular calcification in chronic kidney disease: role of disordered mineral metabolism. Curr Pharm Des. 2014;20(37):5829-33.

11. Vervloet $M$, Cozzolino M. Vascular calcification in chronic kidney disease: different bricks in the wall? Kidney Int. 2017;91(4):808-17.

12. Rezaianzadeh A, Namayandeh S-M, Sadr S-M. National Cholesterol Education Program Adult Treatment Panel III Versus International Diabetic Federation Definition of Metabolic Syndrome, Which One is Associated with Diabetes Mellitus and Coronary Artery Disease? Int J Prev Med. 2012;3(8):552-8.

13. Duhn V, D'Orsi ET, Johnson $S$, et al. Breast arterial calcification: a marker of medial vascular calcification in chronic kidney disease. Clin J Am Soc Nephrol. 2011;6(2):377-82.

14. Hanada $S$, Ando $R$, Naito $S$, et al. Assessment and significance of abdominal aortic calcification in chronic kidney disease. Nephrol Dialysis Transplant. 2010; 25 (6): 1888-95.

15. Górriz JL, Molina P, Cerverón MJ, et al. Vascular calcification in patients with nondialysis CKD over 3 years. Clin J Am Soc Nephrol. 2015;10(4):654-66.

16. Elango K, Javaid A, Khetarpal BK, et al. The Effects of Warfarin and Direct Oral Anticoagulants on Systemic Vascular Calcification: A Review. Cells. 2021; 10 (4): 773.

17. Biyik Z, Selcuk NY, Tonbul HZ, et al. Assessment of abdominal aortic calcification at different stages of chronic kidney disease. Int Urol, Nephrol. 2016;48(12):2061-8.

18. McLenachan S, Camilleri F, Smith $M$, et al. Breast arterial calcification on mammography and risk of coronary artery disease: a SCOT-HEART substudy. Clin Radiol. 2019;74(6):421-8..

19. Yıldız A, Seçen Ö, Yıldız C, Çiçekçi M. Relationship between breast arterial calcification and lipid profile, plasma 
atherogenic index, Castelli's risk index and atherogenic coefficient in premenopausal women. IJC Metab Endocr. 2016;11:19-22.

20. Tantisattamo E, Han KH, O'Neill WC. Increased vascular calcification in patients receiving warfarin. Arterioscler Thromb Vasc Biol. 2015;35(1):23742.

21. T Tesfamariam B. Involvement of Vitamin K-Dependent Proteins in Vascular Calcification. J Cardiovasc Pharmacol Ther. 2019;24(4):323-33.

22. Dhakshinamoorthy J, Elumalai RP, Dev $B$, et al. Assessment of abdominal aortic calcification in predialysis chronic kidney disease and maintenance hemodialysis patients. Saudi J Kidney Dis.Transplant. 2017; 28 (6): 1338.

23. Bureo JC, Arévalo JC, Antón J, et al. Prevalence of secondary hyperparathyroidism in patients with stage 3 and 4 chronic kidney disease seen in internal medicine. Endocrinol Nutr. 2015;62(7):300-5.

24. Semba RD, Fink JC, Sun K, et al. Serum fibroblast growth factor-23 and risk of incident chronic kidney disease in older community-dwelling women. Clin J Am Soc Nephrol. 2012;7(1):85-91.

25. Larsson T, Nisbeth $U$, Ljunggren Ö, et al. Circulating concentration of FGF-23 increases as renal function declines in patients with chronic kidney disease but does not change in response to variation in phosphate intake in healthy volunteers. Kidney Int. 2003; 64 (6):2272-9. 